\title{
Pulsed Field Gradient NMR with Sigmoid Shape Gradient Sampling to Produce More Detailed Diffusion Ordered Spectroscopy Maps of Real Complex Mixtures. Examples with Medicine Analysis.
}

Guilhem Pagès, ${ }^{\dagger \dagger}$ Alice Bonny, ${ }^{\dagger}$ Véronique Gilard, ${ }^{\dagger}$ and Myriam Malet-Martino ${ }^{*},^{\dagger}$

${ }^{\dagger}$ Groupe de RMN Biomédicale, Laboratoire de Synthèse et Physicochimie des Molécules d'Intérêt Biologique UMR CNRS 5068, Université de Toulouse, 118 route de Narbonne, 31062 Toulouse cedex 9, France

* Present address: INRA, UR370 Qualité des Produits Animaux, F-63122 Saint Genès Champanelle, France.

Figure S1. Esomeprazole $40 \mathrm{mg}$ Mylan ${ }^{1} \mathrm{H}$ DOSY maps. 

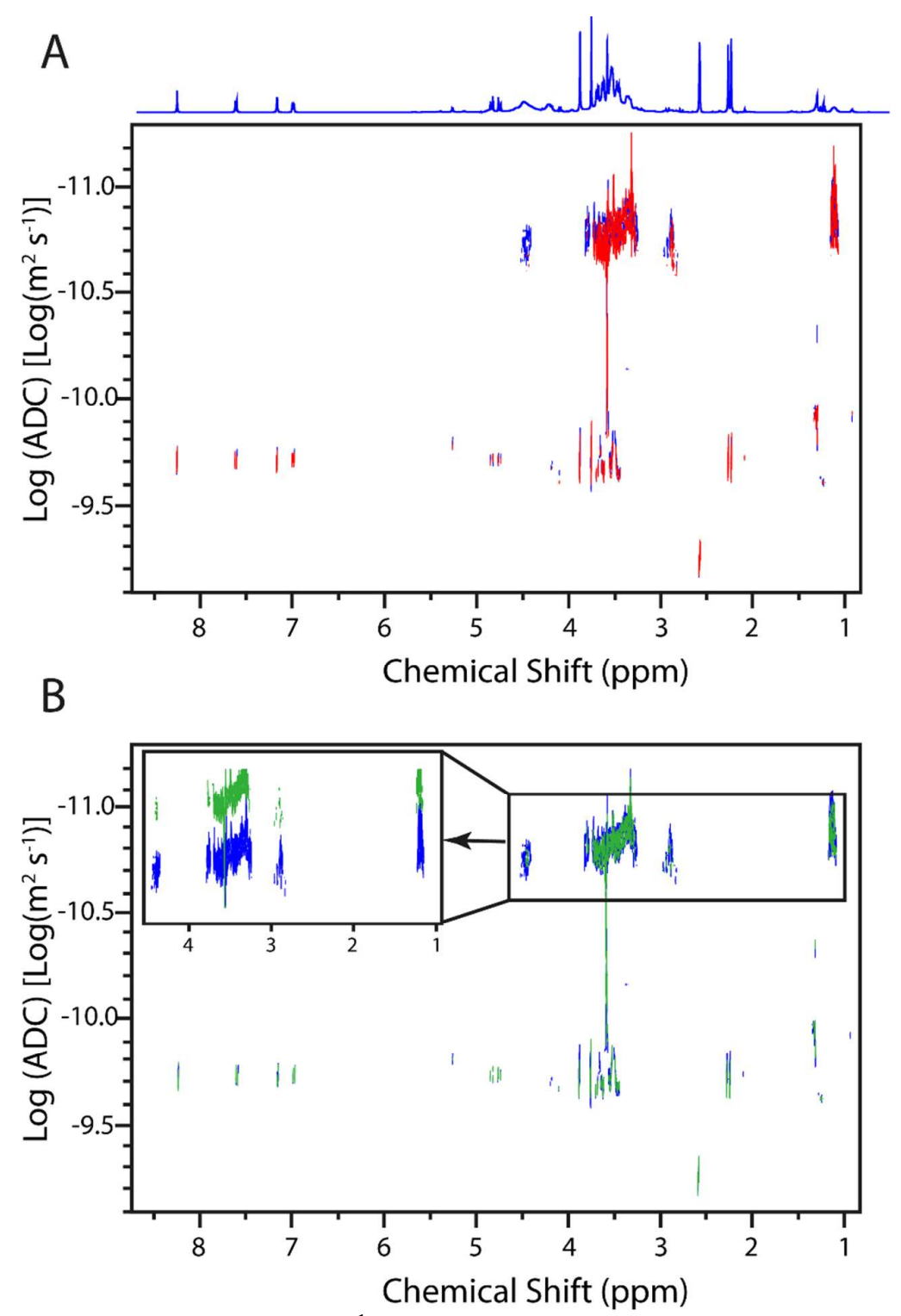

Figure S1. Esomeprazole $40 \mathrm{mg}$ Mylan ${ }^{1} \mathrm{H}$ DOSY maps recorded using the OneShot pulse sequence with 32 gradient increments sampled using a (red) exponential, (green) linear or (blue) semi-gaussian ramp. The sample preparation is described in the manuscript. For a better readability, the inset in B highlights the macromolecule diffusion zone; the map obtained from the linear ramp was shifted upward for an easier comparison. 